\title{
Research on compressive strength of hybrid fiber reinforced concrete based on orthogonal design
}

\author{
HE Tu-sheng ${ }^{1}$, XIE Meng-qian ${ }^{1}$, LIU Yang $^{1}$, ZHAO San-yin $^{1}$, LI Zai-bo ${ }^{1 *}$ \\ ${ }^{1}$ College of Chemistry and Civil Engineering, Shaoguan University, Shaoguan 512005, Guangdong, China
}

\begin{abstract}
The influence of steel fiber and polypropylene fiber mixed on compressive strength of high performance concrete (HPC) was studied. The steel fiber content $(0.5 \%, 1.0 \%, 1.5 \%, 2.0 \%$ ) (volume fraction, the same below), polypropylene fiber content $(0.05 \%, 0.1 \%, 0.15 \%, 0.2 \%)$ and length $(5 \mathrm{~mm}$, $6.5 \mathrm{~mm}, 12 \mathrm{~mm}, 18 \mathrm{~mm}$ ) were studied by $\mathrm{L}_{16}\left(4^{5}\right)$ orthogonal test for $28 \mathrm{~d}$ ages, the range analysis and variance analysis of the test results are carried out, and the prediction model of compressive strength of hybrid fiber reinforced concrete was established. The results show that: The significant influence factor of concrete compressive strength is the volume fraction of polypropylene fiber, while the length of polypropylene fiber and the volume fraction of steel fiber are not significant; the concrete compressive strength with polypropylene fiber shows negative hybrid effect; The prediction model of compressive strength of hybrid fiber reinforced concrete has high accuracy, and the average relative errors is $2.96 \%$.
\end{abstract}

\section{Introduction}

Fiber can improve the tensile, flexural, impact and explosion resistance of concrete[1]. Due to the disordered distribution of fiber in the cement matrix, the friction and sliding between the fiber and the matrix can effectively prevent the formation and expansion of cracks, inhibit the accumulation and development of damage, and ease the stress concentration at the crack tip, so as to improve the toughness of concrete[2]. Adding a specific fiber alone can only improve one aspect of concrete performance[3]. For example, the addition of steel fiber can improve the tensile strength, impact resistance and toughness of concrete, but steel fiber has the disadvantages of easy corrosion, high bulk density, poor performance and so on. Polypropylene fiber can improve the tensile capacity and deformation capacity of concrete, but the elastic modulus and compressive capacity of concrete usually decrease slightly[4]. Mixing two or more kinds of fibers into concrete to make hybrid fiber concrete can effectively solve the above problems, and has better economic benefits[5].

In this paper, based on the previous research work, the compressive strength of 16 groups of hybrid fiber concrete and 1 group of ordinary concrete cube specimens are studied by $\mathrm{L}_{16}\left(4^{5}\right)$ orthogonal design. The factors considered are volume fraction of polypropylene fiber, length of polypropylene fiber and volume fraction of steel fiber, and the influence degree of hybrid fiber on the compressive strength of concrete is found out. The prediction model of compressive strength of hybrid fiber reinforced concrete is established.

\section{Experiment}

\subsection{Raw materials}

The cement $(\mathrm{C})$ is $\mathrm{P} \cdot \mathrm{O} 42.5 \mathrm{R}$, the density is $3.05 \mathrm{~g} / \mathrm{cm}^{3}$, the specific surface area is $385 \mathrm{~m}^{2} / \mathrm{kg}$, and the flexural / compressive strength is $6.2 \mathrm{MPa} / 29.1 \mathrm{MPa}$ and $8.5 \mathrm{MPa}$ / $49.1 \mathrm{MPa}$ for $3 \mathrm{~d}$ and $28 \mathrm{~d}$ ages, respectively. Coarse aggregate $(\mathrm{G})$ is $4.75 \mathrm{~mm}-26.5 \mathrm{~mm}$ continuous graded limestone gravel, apparent density is $2.733 \mathrm{~g} / \mathrm{cm}^{3}$. Fine aggregate is river sand $(\mathrm{S})$, apparent density is 2.692 $\mathrm{g} / \mathrm{cm}^{3}$, the fineness modulus is 3.0 . Additives is polycarboxylate superplasticizer (SP) (ES-600WH, the solid content is $20 \%$ ). The specific surface area is 400 $\mathrm{m}^{2} / \mathrm{kg}$ and the density is $3.40 \mathrm{~g} / \mathrm{cm}^{3}$ of stewed steel slag (SS). S95 grade blast furnace vertical grinding slag (GBFS) density is $2.89 \mathrm{~g} / \mathrm{cm}^{3}$. The basic properties of polypropylene fiber and steel fiber are shown in Table 1.

Table 1. Basic properties of polypropylene fiber

\begin{tabular}{cccc}
\hline Type & $\begin{array}{c}\text { Length } \\
/ \mathrm{mm}\end{array}$ & $\begin{array}{c}\text { Equivalent } \\
\text { diameter } / \mathrm{mm}\end{array}$ & $\begin{array}{c}\text { Density } \\
/ \mathrm{g} / \mathrm{cm}^{3}\end{array}$ \\
\hline $\begin{array}{c}\text { Polypropylene fiber } \\
\text { Steel fiber }\end{array}$ & $5-18$ & 0.045 & 0.91 \\
& 38 & 0.8 & 7.8 \\
\hline
\end{tabular}

\subsection{Concrete mix proportion}

In order to reflect the reinforcement effect of various factors of hybrid fiber on concrete, 16 groups of hybrid fiber concrete and 1 group of ordinary concrete were 
designed. Because of the low volume content of fiber, it has little effect on the volume fraction of the original components of concrete, so when the concrete is formed, except for fiber, other components are the same as the ordinary concrete. According to the JGJ55-2011 industry standard of relevant regulations of mix proportion for design of mix proportion of ordinary concrete and the preliminary test results, the final benchmark concrete mix is shown in Table 2.

Table 2. Concrete mix proportion and $28 \mathrm{~d}$ compressive strength $\left(f_{c}\right)$

\begin{tabular}{|c|c|c|c|c|c|c|c|c|}
\hline \multirow{2}{*}{ No } & \multicolumn{7}{|c|}{ Concrete mix proportion $/ \mathrm{kg} / \mathrm{m}^{3}$} & \multirow{2}{*}{$\begin{array}{c}f_{c} \\
/ \mathrm{MPa}\end{array}$} \\
\hline & $\mathrm{C}$ & SS & GBFS & $\mathrm{S}$ & W & G & SP & \\
\hline L0 & 288 & 57.6 & 134.4 & 734 & 135 & 1102 & 7.20 & 61.5 \\
\hline
\end{tabular}

\subsection{Orthogonal test design}

In order to compare the influence of various factors of hybrid fiber on the compressive strength of concrete, and find out the better mix proportion of hybrid fiber reinforced concrete, three factors are determined: (1) Volume fraction of polypropylene fiber $\left(\mathrm{V}_{\mathrm{A}}\right)$; (2) Polypropylene fiber length $\left(\mathrm{L}_{\mathrm{B}}\right)$; (3) Volume fraction of steel fiber $\left(\mathrm{V}_{\mathrm{C}}\right)$. According to the orthogonal test method, L16 $\left(4^{5}\right)$ orthogonal table is used to arrange the test, and the orthogonal test factors and levels are shown in Table 3 .

\subsection{Test method}

The samples shall be made in accordance with the relevant provisions of CECS13:2009 standard for test methods of fiber reinforced concrete, the sample specification is $100 \mathrm{~mm} \times 100 \mathrm{~mm} \times 100 \mathrm{~mm}$ test block, and the formwork shall be removed 24 hours after the test block is made, and the standard curing shall be 28 days. The compressive strength shall be determined in accordance with GB / T 50081-2019 standard for mechanical properties of ordinary concrete.

\section{Test results and analysis}

\subsection{Test results}

Compressive strength test shall be carried out on the concrete specimen after curing for $28 \mathrm{~d}$ ages under standard conditions, its compressive strength $\left(f_{c}\right)$ is shown in Table 3.

Table 3. Orthogonal test scheme and test results

\begin{tabular}{ccccccc}
\hline & & & & & & \\
Number & $\mathrm{A}$ & $\mathrm{B}$ & $\mathrm{C}$ & $\mathrm{E}$ & $\mathrm{F}$ & $f_{c}$ \\
& $\mathrm{~V}_{\mathrm{A}} / \%$ & $\mathrm{~L}_{\mathrm{B}} / \mathrm{mm}$ & $\mathrm{V}_{\mathrm{C}} / \%$ & Blank & Blank & $/ \mathrm{MPa}$ \\
\hline $\mathrm{L} 1$ & $1(0.05)$ & $1(5.0)$ & $1(0.5)$ & 1 & 1 & 62.6 \\
$\mathrm{~L} 2$ & $1(0.05)$ & $2(6.5)$ & $2(1.0)$ & 2 & 2 & 64.0 \\
\hline
\end{tabular}

\begin{tabular}{ccccccc}
\hline L3 & $1(0.05)$ & $3(12)$ & $3(1.5)$ & 3 & 3 & 61.3 \\
L4 & $1(0.05)$ & $4(18)$ & $4(2.0)$ & 4 & 4 & 60.8 \\
L5 & $2(0.10)$ & $1(5.0)$ & $2(1.0)$ & 3 & 4 & 58.6 \\
L6 & $2(0.10)$ & $2(6.5)$ & $1(0.5)$ & 4 & 3 & 59.3 \\
L7 & $2(0.10)$ & $3(12)$ & $4(2.0)$ & 1 & 2 & 57.5 \\
L8 & $2(0.10)$ & $4(18)$ & $3(1.5)$ & 2 & 1 & 67.4 \\
L9 & $3(0.15)$ & $1(5.0)$ & $3(1.5)$ & 4 & 2 & 59.5 \\
L10 & $3(0.15)$ & $2(6.5)$ & $4(2.0)$ & 3 & 1 & 61.8 \\
L11 & $3(0.15)$ & $3(12)$ & $1(0.5)$ & 2 & 4 & 55.9 \\
L12 & $3(0.15)$ & $4(18)$ & $2(1.0)$ & 1 & 3 & 58.9 \\
L13 & $4(0.20)$ & $1(5.0)$ & $4(2.0)$ & 2 & 3 & 54.2 \\
L14 & $4(0.20)$ & $2(6.5)$ & $3(1.5)$ & 1 & 4 & 56.5 \\
L15 & $4(0.20)$ & $3(12)$ & $2(1.0)$ & 4 & 1 & 55.9 \\
L16 & $4(0.20)$ & $4(18)$ & $1(0.5)$ & 3 & 2 & 57.0 \\
\hline
\end{tabular}

\subsection{Visual analysis}

According to the analysis method of orthogonal test, the results in Table 3 are processed, and the visual analysis table of orthogonal test is obtained, as shown in Table 4.

Table 4. Visual analysis of compressive strength

\begin{tabular}{ccccccc}
\hline Index & Factor & $\mathrm{k} 1$ & $\mathrm{k} 2$ & $\mathrm{k} 3$ & $\mathrm{k} 4$ & Range R \\
\hline \multirow{2}{*}{$f_{c}$} & $\mathrm{~A}$ & 62.18 & 60.68 & 59.00 & 55.91 & 6.27 \\
$/ \mathrm{MPa}$ & $\mathrm{B}$ & 58.73 & 60.40 & 57.62 & 61.01 & 3.40 \\
& $\mathrm{C}$ & 58.69 & 59.35 & 61.16 & 58.57 & 2.59 \\
\hline
\end{tabular}

From the range values of various factors of compressive strength in Table 4, it can be seen that the volume fraction of polypropylene fiber has the greatest influence on the compressive strength of concrete, followed by the length of polypropylene fiber, and finally the volume fraction of steel fiber.

\subsection{Variance analysis}

Variance analysis of compressive strength of hybrid fiber reinforced concrete for $28 \mathrm{~d}$ ages are shown in Table 5 . If $\mathrm{F}_{0.01}\left(\mathrm{f}_{1}, \mathrm{f}_{2}\right)<\mathrm{F}$, the influence of representative factors on the test results is "very significant", indicated by "**"; If $\mathrm{F}_{0.05}\left(\mathrm{f}_{1}, \mathrm{f}_{2}\right)<\mathrm{F}<\mathrm{F}_{0.01}\left(\mathrm{f}_{1}, \mathrm{f}_{2}\right)$, it indicates that the influence of factors on the test results is "significant", which is indicated by "*"; If $F<F_{0.05}\left(f_{1}, f_{2}\right)$, it indicates that the influence of factors on the test results is "non significant". When the factor has little influence on the test results, the factor and error e are combined into a new error $\mathrm{e}^{\Delta}$.

Table 5. Variance analysis of compressive strength

\begin{tabular}{cccccc}
\hline $\begin{array}{c}\text { Difference } \\
\text { source }\end{array}$ & SS & df & MS & F & S \\
\hline $\mathrm{A}$ & 86.84 & 3 & 28.95 & 4.30 & $*$ \\
$\mathrm{~B}$ & 28.85 & 3 & 9.62 & 1.43 & \\
$\left.\mathrm{C}_{\text {Error }}\right\}$ Error $\mathrm{e}^{\Delta}$ & $\left.\begin{array}{c}17.13 \\
43.40\end{array}\right\} 60.53$ & $\left.\begin{array}{l}3 \\
6\end{array}\right\} 9$ & 6.73 & & \\
\hline
\end{tabular}

$F: \overline{F_{0.01}(3,9)}=6.99, F_{0.05}(3,9)=3.86$. 
It can be seen from Table 5 that the volume fraction of polypropylene fiber has a "significant" impact on the 28d compressive strength of concrete; the length of polypropylene fiber is the second, and the volume fraction of steel fiber has the smallest impact (combined with the error column into a new error $\mathrm{e}^{\Delta}$ ), which is consistent with the results of range analysis.

\subsection{Factor index analysis}

In order to facilitate the analysis of the relationship between various factors and performance indexes such as $28 \mathrm{~d}$ compressive strength of concrete, the trend chart of each factor at different levels is drawn from the visual analysis table, as shown in Figure 1.
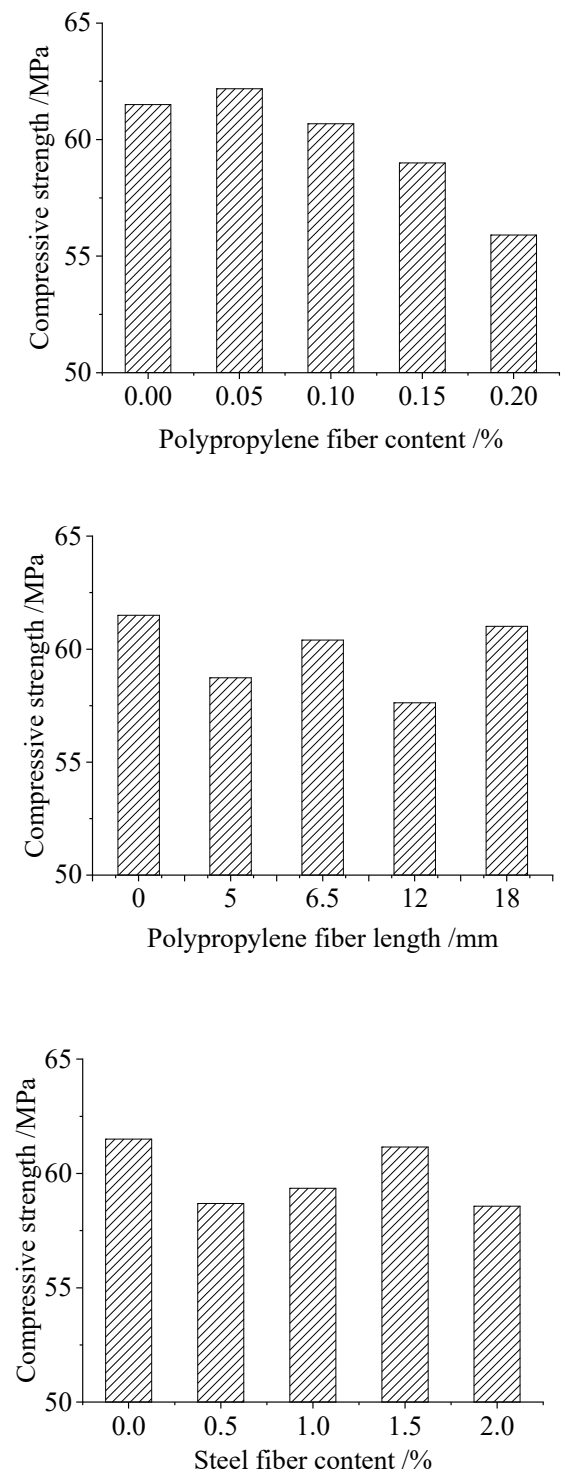

Figure. 1. Influence of three factors on compressive strength of concrete

It can be seen from Figure 1 and Table 4 that: (1) when the volume fraction of polypropylene fiber increases from $0.05 \%$ to $0.2 \%$, the compressive strength of concrete decreases regularly by $10.1 \%$, so the compressive strength of concrete mixed with polypropylene fiber shows negative hybrid effect. The main reason is that after adding the fiber, the concrete has "initial defect". Because of the air entrainment of polypropylene fiber, the binding force between the cementitious material and the aggregate of the concrete decreases, resulting in the reduction of the compressive strength of the concrete. (2) when the length of polypropylene fiber is increased from $5 \mathrm{~mm}$ to $18 \mathrm{~mm}$, the maximum compressive strength of concrete can be increased by $3.9 \%$, and the increase range is limited. According to the analysis of variance, the influence of polypropylene fiber length on the compressive strength of concrete is "non significant". (3) when the volume fraction of steel fiber is increased from $0.5 \%$ to $2.0 \%$, the compressive strength of concrete has the maximum value, that is, the content of steel fiber is $1.5 \%$, the compressive strength of concrete is $61.16 \mathrm{MPa}$, increased by $4.2 \%$.

Compared with the ordinary concrete, when the volume fraction of polypropylene fiber is $0.05 \%$, the length is $18 \mathrm{~mm}$, and the volume fraction of steel fiber is $1.5 \%$, the compressive strength of concrete is the largest, which is increased by $1.1 \%,-0.8 \%$ and $-0.6 \%$ respectively; If the compressive strength of concrete is considered only, the preferred option is $\mathrm{A}_{1} \mathrm{~B}_{4} \mathrm{C}_{3}$.

\section{Prediction model}

According to the theory of composite mechanics, it can be assumed that matrix strength, polypropylene fiber content, polypropylene fiber length and steel fiber content are the four parts of hybrid fiber-reinforced concrete strength. The strength regression equation is assumed to be:

$$
f=f_{0}+\alpha \cdot V_{A}+\beta \cdot L_{B}+\gamma \cdot V_{C}
$$

Where: $f$ is the cube compressive strength (MPa); $f_{0}$ is the cube compressive strength (MPa); $\alpha, \beta, \gamma$ are regression coefficients; $V_{A}$ is the volume fraction of polypropylene fiber (\%); $L_{B}$ is the length of polypropylene fiber $(\mathrm{mm}) ; V_{C}$ is the volume fraction of steel fiber $(\%)$.

The data in Table 3 are substituted into regression equation (1), and regression equations of compressive strength of hybrid fiber reinforced concrete is obtained by Mintab software as follows:

$$
f_{C}=63.29-41.0 V_{A}+0.089 L_{B}+0.29 V_{C}
$$

In equations (2): $f_{c}$ is the concrete cube compressive strength $(\mathrm{MPa})$.

Table 6. Measured value, predicted value and relative error of compressive strength of concrete

\begin{tabular}{cccc}
\hline \multirow{2}{*}{$\begin{array}{c}\text { Test } \\
\text { number }\end{array}$} & \multicolumn{2}{c}{ 28d compressive strength $/ \mathrm{MPa}$} & \\
\cline { 2 - 3 } & Measured value & Predicted value & \\
\hline L1 & 62.6 & 61.83 & $1.23 \%$ \\
L2 & 64.0 & 62.11 & $2.96 \%$ \\
L3 & 61.3 & 62.74 & $-2.35 \%$ \\
L4 & 60.8 & 63.42 & $-4.31 \%$
\end{tabular}




\begin{tabular}{cccc} 
L5 & 58.6 & 59.93 & $-2.26 \%$ \\
L6 & 59.3 & 59.91 & $-1.03 \%$ \\
L7 & 57.5 & 60.84 & $-5.80 \%$ \\
L8 & 67.4 & 61.22 & $9.16 \%$ \\
L9 & 59.5 & 58.02 & $2.49 \%$ \\
L10 & 61.8 & 58.30 & $5.67 \%$ \\
L11 & 55.9 & 58.35 & $-4.39 \%$ \\
L12 & 58.9 & 59.03 & $-0.22 \%$ \\
L13 & 54.2 & 56.12 & $-3.53 \%$ \\
L14 & 56.5 & 56.10 & $0.70 \%$ \\
L15 & 55.9 & 56.45 & $-0.98 \%$ \\
L16 & 57.0 & 56.83 & $0.29 \%$ \\
\hline
\end{tabular}

It can be seen from table 6 that the relative errors of the established prediction models for compressive strength of hybrid fiber-reinforced concrete are mostly within $10 \%$, and the average value of the absolute values of the relative errors is $2.96 \%$, which shows that the model has high accuracy.

\section{Conclusions}

(1) The volume fraction of polypropylene fiber has a significant impact on compressive strength of concrete for $28 \mathrm{~d}$ ages, the length of polypropylene fiber is the second, and the volume fraction of steel fiber has the smallest impact.

(2) The prediction model of compressive strength of hybrid fiber-reinforced concrete has high accuracy, and the average relative errors is $2.96 \%$.

\section{Acknowledgements}

This research was financially supported by Natural Science Foundation of Guangdong under grant No. 2020A1515011221, Characteristic Innovation Talent Program of Guangdong under grant No. 2019KTSCX163, Science and Technology Project of Shaoguan under grant No. 2019sn060 and 2019CS05308, Innovation and Entrepreneurship Training Program for College Students of Guangdong Province under grant No. S202010576026.

\section{References}

1. Wu, Z.; Shi, C.; He, W. (2016) Effects of steel fiber content and shape on mechanical properties of ultra high performance concrete. J. Constr. Build. Mater., 103: 8-14.

2. Jing jun, Li, Jian gang, Niu, Chao jun Wan, et al. (2016) Investigation on mechanical properties and microstructure of high performance polypropylene fiber reinforced lightweight aggregate concrete. J. Constr. Build. Mater., 118: 27-35.
3. Ali, M.A.E.M., Soliman, A.M., Nehdi, M. L. (2017) Hybrid-fiber reinforced engineered cementitious composite under tensile and impact loading. J. Mater. Design., 117: 139-149.

4. Zhou Y, Xi B, Yu K, Sui L, Xing F. (2018) Mechanical properties of hybrid ultra-high performance engineered cementitous composites incorporating steel and polyethylene fibers. J. Mater., 11(8): 1448.

5. Wang D, Ju Y Z, Shen H, et al. (2019) Mechanical properties of high performance concrete reinforced with basalt fiber and polypropylene fiber. J. Constr. Build. Mater., 197: 464-47. 